Article (refereed)

Hunter, Peter D.; Tyler, Andrew N.; Carvalho, Laurence; Codd, Geoffrey A.; Maberly, Stephen C.. 2010 Hyperspectral remote sensing of cyanobacterial pigments as indicators for cell populations and toxins in eutrophic lakes. Remote Sensing of Environment, 114. 2705-2718. 10.1016/j.rse.2010.06.006

Copyright $\odot 2010$ Elsevier B.V.

This version available $h$ ttp://nora.nerc.ac.uk/10886/

NERC has developed NORA to enable users to access research outputs wholly or partially funded by NERC. Copyright and other rights for material on this site are retained by the authors and/or other rights owners. Users should read the terms and conditions of use of this material at http://nora.nerc.ac.uk/policies.html\#access

This document is the author's final manuscript version of the journal article, incorporating any revisions agreed during the peer review process. Some differences between this and the publisher's version remain. You are advised to consult the publisher's version if you wish to cite from this article.

www.elsevier.com/

\author{
Contact CEH NORA team at \\ noraceh@ceh.ac.uk
}

The NERC and CEH trade marks and logos ('the Trademarks') are registered trademarks of NERC in the UK and other countries, and may not be used without the prior written consent of the Trademark owner. 


\section{Hyperspectral remote sensing of cyanobacterial pigments}

\section{2 as indicators for cell populations and toxins in eutrophic}

\section{3 lakes}

4

5 Peter D. Hunter ${ }^{\mathrm{a}, *}$, Andrew N. Tyler ${ }^{\mathrm{a}}$, Laurence Carvalho ${ }^{\mathrm{b}}$, Geoffrey A. Codd $^{\mathrm{c}}$ and Stephen C.

6 Maberly $^{\mathrm{d}}$

7

$8{ }^{\mathrm{a}}$ School of Biological and Environmental Science, University of Stirling, Stirling,

$9 \quad$ FK9 4LA, United Kingdom.

10

$11{ }^{\mathrm{b}}$ Centre for Ecology \& Hydrology, Bush Estate, Penicuik, Midlothian,

12 EH26 0QB, United Kingdom.

13

$14{ }^{\mathrm{c} D}$ Division of Molecular Microbiology, College of Life Sciences, University of Dundee,

15 Dundee, DD1 5EH, United Kingdom.

16

$17{ }^{\mathrm{d}}$ Centre for Ecology \& Hydrology, Lancaster Environment Centre, Library Avenue, Bailrigg, 18 Lancaster, LA1 4AP, United Kingdom.

*Corresponding author. Tel.: +44 1786 467810; fax: +44 1786467843.

E-mail address: p.d.hunter@stir.ac.uk 


\section{Abstract}

2 The growth of mass populations of toxin-producing cyanobacteria is a serious concern for the

3 ecological status of inland waterbodies and for human and animal health. In this study we

4 examine the performance of four semi-analytical algorithms for the retrieval of chlorophyll $a$

5 (Chl $a$ ) and phycocyanin (C-PC) from data acquired by the Compact Airborne Spectrographic

6 Imager-2 (CASI-2) and the Airborne Imaging Spectrometer for Applications (AISA) Eagle

7 Sensor. The retrieval accuracies are compared to those returned by semi-empirical band-ratio

8 algorithms optimised for these datasets. The best-performing algorithm for the retrieval of

9 Chl $a$ was a semi-empirical band-ratio model $\left(\mathrm{R}^{2}=0.832 ; \mathrm{RMSE}=29.8 \%\right)$. The best

10 performing model for the retrieval of C-PC was a semi-analytical nested band ratio model $\left(\mathrm{R}^{2}\right.$

$11=0.984 ; \mathrm{RMSE}=3.98 \mathrm{mg} \mathrm{m}^{-3}$ ). The concentrations of $\mathrm{C}-\mathrm{PC}$ retrieved using the semi-

12 analytical model were also correlated with those of cyanobacterial cells $\left(\mathrm{R}^{2}=0.380\right)$ and of

13 the particulate and total (particulate plus dissolved) pools of microcystins $\left(\mathrm{R}^{2}=0.858\right.$ and

140.896 respectively). Importantly, both the semi-empirical and semi-analytical algorithms

15 were able to retrieve the concentration of C-PC at cyanobacterial cell concentrations below

16 current warning thresholds for cyanobacteria in waterbodies. This demonstrates the potential

17 of remote sensing to contribute to early-warning detection and monitoring of cyanobacterial

18 blooms for human health protection, at regional and global scales.

20 Key words: Cyanobacteria; human health; lakes; microcystin; imaging spectrometry; risk 21 assessment 


\section{Introduction}

\subsection{Mass populations of toxic cyanobacteria}

3 Cyanobacteria (blue-green algae) are natural and cosmopolitan inhabitants of fresh, brackish

4 and marine waters. They are particularly well adapted for growth in nutrient-enriched lakes

5 and other slow-flowing inland waters and often form mass populations (as blooms, scums or

6 biofilms) during summer and autumn in temperate latitudes. These mass populations are a

7 serious concern because they can have profound and far-reaching adverse environmental and

8 economic impacts on natural and controlled waterbodies (Pearson et al., 2001; Havens,

9 2008). Cyanobacterial populations can also pose significant risks to animal and human health

10 because several species can produce potent toxins (cyanotoxins). These toxins constitute

11 some of the most hazardous of all waterborne biological substances and include agents with

12 (examples in parentheses): neurotoxic (anatoxin-a, anatoxin-a[S], beta-methylamino alanine,

13 saxitoxins); hepatotoxic and tumour-promoting (microcystins, nodularins); cytotoxic and

14 genotoxic (cylindrospermopsins), and endotoxic (lipopolysaccharides) properties (Codd et

15 al., 2005b; Metcalf et al., 2008). The microcystins (MC), of which over 90 structural variants

16 are known, are among the most common and potent of the cyanotoxins.

18 Blooms of toxigenic cyanobacteria in waterbodies used for drinking water, aquaculture, crop

19 irrigation and recreation are increasing in abundance and spread due to eutrophication.

20 Human exposure to bloom-forming cyanobacteria and their toxins most commonly occurs via

21 drinking water or incidental ingestion, dermal contact and inhalation (Codd et al., 2005b).

22 However, there is also evidence that cyanotoxins can be transferred to crops intended for

23 human consumption via spray-irrigation with contaminated water (Codd et al., 1999; Tyler et

24 al., 2009). Cyanotoxins have been linked with numerous incidences of ill health in humans,

25 ranging from cases of mild skin irritation and gastrointestinal illnesses to acute (and 
1 occasionally fatal) poisonings (Pilotto et al., 1997; Carmichael et al., 2001). These health

2 risks may be further exacerbated if incidences of blooms continue to increase under a

3 warming climate (Johnk et al., 2008; Paerl \& Huisman, 2008).

5 Cyanobacterial abundance is a useful indicator of inland and coastal water quality and is one

6 of the biological quality metrics being considered for the assessment of lake ecological status

7 under the European Union's Water Framework Directive (EU WFD) (2000/60/EC). The

8 monitoring of cyanobacteria and cyanotoxins is also necessary so that timely warnings can be

9 provided to safeguard animal and human health. Cyanotoxin concentrations are rarely

10 routinely monitored in waterbodies as the analyses are costly, and require specialist

11 laboratory facilities and technical expertise. Consequently, existing monitoring programmes tend to focus on cyanobacterial cell numbers (or biovolume) rather than cyanotoxin identification and quantification. The resource costs involved in both sampling lakes and analysing cyanobacterial densities, limits agencies across Europe to generally only monitor a

15 single location, from a small proportion of lakes at a monthly frequency at best.

16 Consequently, conventional monitoring programmes are only aimed at providing a general assessment of ecological quality at these lakes and are insufficient to provide timely warnings of bloom development across whole lake areas or across large geographical regions.

There is a clear need to develop techniques that can complement and extend current approaches to monitoring and managing cyanobacteria and their toxins in inland, transitional and coastal waters. Indeed, this has recently been acknowledged by a number of international bodies (WHO, 2003, 2004; Codd et al., 2005a). Techniques including flow cytometry and spectrofluorometry (with specificity for diagnostic cyanobacterial pigments) offer possibilities for real-time monitoring of cyanobacteria in the field. However, such techniques 
1 can be less effective where monitoring needs to be undertaken routinely across numerous

2 lakes at a regional or national scale. Moreover, as cyanobacterial bloom and scum

3 distribution can change rapidly in space and time, e.g. according to wind speed and direction,

4 observations at fixed stations or along set transects may be unrepresentative of cyanobacterial

5 distribution and abundance throughout the entire waterbody (Rantajarvi et al., 1998; Kutser,

$62004)$.

7

8 In view of this, there is considerable interest in developing remote sensing-based techniques

9 to detect and map cyanobacterial blooms from space. Recent advances in ocean colour

10 remote sensing have demonstrated that it is possible to develop bespoke inversion algorithms

11 for mapping different phytoplankton functional types (PFTs) and size classes (Nair et al.,

12 2008) and to recognise important bloom-forming species including coccolithophores (Smyth

13 et al., 2002), diatoms (Sathyendranath et al., 2004) red tide dinoflagellates (Tomlinson et al.,

14 2009) and toxigenic cyanobacteria (Ramos et al., 2005; Westberry et al., 2005). Similarly, in

15 inland waters there is a small but growing body of evidence to suggest that the identification

16 and quantification of cyanobacteria is possible from measurements of remote-sensing-

17 reflectance $\left(R_{\mathrm{rs}}\left(0^{+}, \lambda\right)\right)$ because of their unique bio-optical traits (Hunter et al., 2008a; Kutser

18 et al., 2006; Reinart \& Kutser, 2006). A comprehensive review of recent progress in this

19 field can be found in Kutser (2009).

\subsection{Remote sensing of cyanobacterial blooms}

22 Chl $a$ concentration is used as a standard measure of phytoplankton biomass in fresh and

23 marine waters and numerous inversion algorithms for the retrieval of $\mathrm{Chl} a$ from

24 measurements of $R_{\mathrm{rs}}\left(0^{+}, \lambda\right)$ have been developed for both Case 1 waters (those waters whose optical properties are determined primarily by phytoplankton and covarying coloured 
1 dissolved organic matter and detrital material (CDOM)), and Case 2 waters (whose optical

2 properties are significantly influenced by other constituents such as mineral particles and

3 CDOM that do not covary with phytoplankton concentration) (Gons, 1999; Tyler et al.,

4 2006). Because Chl $a$ is almost ubiquitous across phytoplankton, the retrieval of Chl $a$ alone

5 does not provide any information on the presence and abundance of specific taxa. However,

6 the development of new inversion algorithms for the retrieval of the cyanobacterial biomarker

7 pigment C-phycocyanin (C-PC) from $R_{\mathrm{rs}}\left(0^{+}, \lambda\right)$ offers a route to detect and quantify

8 cyanobacterial biomass in inland and coastal waters. To date, three different types of

9 inversion algorithms have been developed for the retrieval of C-PC over turbid inland waters.

10 These include the baseline algorithm proposed by Dekker (1993), the band-ratio algorithms

11 for C-PC retrieval of Schalles et al. (2000) and Hunter et al. (2008b; 2009), and the semi-

12 empirical nested band-ratio of Simis et al. (2005) (hereafter referred to as the SIMIS

13 algorithm).

15 The SIMIS semi-analytical nested band-ratio algorithm retrieves the value of C-PC absorption coefficient at $620 \mathrm{~nm}$. It includes a correction for absorption by Chl $a$ at the 620 nm C-PC absorption maximum. The algorithm is based on an earlier model for $\mathrm{Chl} a$ retrieval developed by Gons (1999) for MERIS (Medium Resolution Imaging Spectrometer)

19 onboard the European Space Agency's Envisat (hereafter referred to as the GONS

20 algorithm). These algorithms exploit the relationship between subsurface irradiance reflectance and the absorption and backscattering properties of optically-active constituents in the water column as defined by Gordon et al. (1975):

$$
R(0-, \lambda)=f \frac{b_{b}(\lambda)}{a(\lambda)+b_{b}(\lambda)}
$$


2 Where $f$ is an empirically determined scale factor dependent on the ambient light field and

$3 a(\lambda)$ and $b_{b}(\lambda)$ are the coefficients for total absorption and backscattering respectively. If $f$

4 and $b_{b}$ are assumed to be spectrally-independent, and $b_{b}$ is known for a particular wavelength,

5 then absorption by water and its main constituents can be solved from the ratio $R\left(\lambda_{2}\right): R\left(\lambda_{1}\right)$

6 and a known value for $a$ at wavelength $\lambda_{2}$ :

7

$$
a\left(\lambda_{1}\right)=\left\{\left[a\left(\lambda_{2}\right)+b_{b}\right] \times\left[\frac{R\left(\lambda_{2}\right)}{R\left(\lambda_{1}\right)}\right]\right\}-b_{b}
$$

10 The GONS algorithm uses the ratio of reflectance for $\lambda_{1}=665$ and $\lambda_{2}=709 \mathrm{~nm}$ to estimate

11 the Chl $a$ absorption coefficient at $665 \mathrm{~nm}$. It assumes that $a\left(\lambda_{1}\right)$ can be attributed to

12 absorption by water $\left[a_{w}\left(\lambda_{1}\right)\right]$ and phytoplankton pigments $\left[a_{\mathrm{ph}}\left(\lambda_{1}\right)\right]$, and that $a\left(\lambda_{2}\right)$ can be

13 attributed entirely to absorption by water $\left[a_{\mathrm{w}}\left(\lambda_{2}\right)\right]$. This ignores the possible contributions of

14 non-phytoplankton particulates (inorganic and organic suspended particulate matter) and

15 CDOM to $a\left(\lambda_{1}\right)$ and $a\left(\lambda_{2}\right)$. It also assumes that absorption by phytoplankton pigments is

16 negligible at $a\left(\lambda_{2}\right)$. The empirical correction factor $\gamma$ is introduced to relate absorption at $\lambda_{1}$ to

17 that measured at the same wavelength. The following relationship for the retrieval of Chl $a$

18 absorption at $665 \mathrm{~nm}\left[a_{\mathrm{chl}}(665)\right]$ is then obtained:

$$
a_{\mathrm{chl}}(665)=\left(\left\{\left[a_{w}(709)+b_{b}\right] \times\left[\frac{R(709)}{R(665)}\right]\right\}-b_{b}-a_{w}(665)\right) \times ?^{-1}
$$


1 The value of $b_{b}$ is estimated according to Gons $(1999 ; 2005)$ by using a wavelength further

2 into the NIR and inverting Eq. (1) using an estimate of $f$ based upon an empirical relation

3 incorporating the average cosine of downward irradiance:

4

$$
b_{b}(779)=\frac{1.61 \times R(779)}{0.082-0.6 \times R(779)}
$$

6

7 The concentration of $\mathrm{Chl} a$ is then returned by dividing $a_{\mathrm{chl}}(665)$ by the specific absorption coefficient of Chl $a$ at $665 \mathrm{~nm}\left(a_{\mathrm{chl}}^{*}(665)\right)$ as shown below:

9

$$
\text { Chl } a=a_{\mathrm{chl}}(665) / a_{\mathrm{chl}}^{*}(665)
$$

12 The above algorithm was modified in Simis et al. (2005) for the retrieval of C-PC through the

13 introduction of the ratio of reflectance at $\lambda_{1}=620$ and $\lambda_{2}=709 \mathrm{~nm}$ and an empirically

14 derived factor $\delta$ for the correction of $a(620)$ that mimics the use of the constant $\gamma$ used in Eq.

15 3. To account for co-absorption by Chl $a$ and C-PC at $620 \mathrm{~nm}$ it is necessary firstly to

16 estimate absorption by $\mathrm{Chl} a$ at $620 \mathrm{~nm}\left[a_{\mathrm{chl}}(620)\right]$ and then subtract this from $a(620)$ to yield

17 the absorption by C-PC $\left[a_{\mathrm{CPC}}(620)\right]$. This is achieved by the introduction of the conversion

18 factor $\varepsilon$ that relates in vivo absorption by $\mathrm{Chl} a$ at $665 \mathrm{~nm}$ to that at $620 \mathrm{~nm}$. Subsequently,

$19 a_{\mathrm{CPC}}(620)$ can be solved from:

20

$$
a_{\mathrm{CPC}}=\left(\left\{\left[a_{w}(709)+b_{b}\right] \times\left[\frac{R(709)}{R(620)}\right]\right\}-b_{b}-a_{w}(620)\right) \times ?^{-1}-\left[? \times a_{\mathrm{chl}}(665)\right]
$$


1 by substitution of $a_{w}(620)=0.281, a_{w}(665)=0.401$ and $a_{w}(709)=0.727$ from Buiteveld et al.

2 (1994) and $\delta=0.84, \gamma=0.68$ and $\varepsilon=0.24$ from Simis et al. (2005). The concentration of C-

$3 \mathrm{PC}$ is retrieved by dividing by the specific absorption coefficient for C-PC at $620 \mathrm{~nm}$ :

4

$$
\mathrm{CPC}=a_{\mathrm{CPC}}(620) / a_{\mathrm{CPC}}^{*}(620)
$$

7 The inversion algorithm developed by Simis et al. (2005) has recently been tested using extensive in-situ radiometric measurements at a series of lakes and reservoirs in the

9 Netherlands, Spain and the United States (c.f., Randolph et al., 2008; Ruiz-Verdu et al., 2008;

10 Simis et al., 2007) and was found to outperform other algorithms for C-PC retrieval. The inversion algorithm was also recently successfully used to retrieve C-PC estimates from MERIS data \{Guanter et al. 2010\}. The wider testing of this algorithm for the retrieval of CPC from $R_{\mathrm{rs}}\left(0^{+}, \lambda\right)$ spectra measured by airborne and spaceborne sensors is necessary because the incursion of errors due to atmospheric and adjacency effects can have a significant effect on the estimation of pigment concentrations from remotely sensed data (Alikas \& Reinart, 2008).

In addition to the bespoke algorithm for the retrieval of C-PC of Simis et al. (2005), a medium-independent model to retrieve pigment concentrations has been developed by Dall'Olmo et al. (2003). This model uses the value of $R_{\mathrm{rs}}\left(0^{+}, \lambda\right)$ in three bands to estimate the 21 pigment concentrations: 
1 The specific wavelengths used in the model must be optimised for the pigment of interest

2 through empirical iteration. Dall'Olmo et al. (2003) developed the algorithm originally for

3 the retrieval of $\mathrm{Chl} a$ in terrestrial vegetation and turbid inland waters. The theory behind the

4 model is that the reciprocal of reflectance at wavelength $\lambda_{1}$ should be maximally sensitive to

5 absorption by the pigment of interest. Dall'Olmo and Gitelson (2005) suggest a wavelength

6 between 660 to $690 \mathrm{~nm}$ for the retrieval of $\mathrm{Chl} a$. However, as reflectance in this spectral

7 region is also affected to varying degrees by absorption by mineral particles, organic detritus

8 and CDOM, a second wavelength, $\lambda_{2}$, that is minimally sensitive to absorption by the

9 pigment of interest, and is close to $\lambda_{1}$, is needed to correct for co-absorption by other

10 optically-active constituents. It has been shown that $\lambda_{2}$ should occur between 710 to $730 \mathrm{~nm}$

11 for the retrieval of Chl $a$ (Dall'Olmo \& Gitelson, 2006; Gitelson et al., 2006).

13 To account for potential differences in backscattering, potentially caused by non-

14 phytoplankton particulates, a third wavelength $\lambda_{3}$ is introduced into the model at which absorption is dominated by water (i.e. $\lambda_{3}$ should be minimally sensitive to absorption by

16 pigments, mineral particles, organic detritus and CDOM). Dall'Olmo and Gitelson (2005)

17 located $\lambda_{3}$ between 740 and $760 \mathrm{~nm}$.

The semi-analytical algorithm derived by Dall'Olmo (2003) has been well-validated for the retrieval of Chl $a$ using empirical datasets and radiative transfer modelling (Dall'Olmo \&

21 Gitelson, 2005; Dall'Olmo \& Gitelson, 2006; Gitelson et al., 2008). Hunter et al. (2008a)

22 previously adapted this algorithm to estimate C-PC concentrations in experimental cultures of 23 cyanobacteria. This was achieved by setting $\lambda_{1}=630, \lambda_{2}=660$ and $\lambda_{3}=750 \mathrm{~nm}$ after

24 iterative tuning of the algorithm. However, the ability of the algorithm to estimate C-PC in 25 natural inland waters has yet to be examined. 
2 In the present study, we test the performance of the semi-analytical algorithms of Gons

3 (1999), Simis et al. (2005) and Dall'Olmo et al (2003) for the retrieval of Chl $a$ and C-PC in

4 inland waters using imagery from the Compact Airborne Spectrographic Imager-2 (CASI-2)

5 and the hyperspectral Airborne Imaging Spectrometer for Applications (AISA) Eagle and

6 Hawk sensors. We compare their performance to that of several semi-empirical algorithms

7 optimised for our specific dataset. We also analyse the relationships between the estimated

8 C-PC concentrations and the measured concentrations of cyanobacterial cells and toxins

9 (microcystins). The potential utility of remote sensing as a means of monitoring

10 cyanobacterial blooms in inland waters is discussed and some directions for future research

11 are outlined.

\section{2. Methods}

\section{$14 \quad 2.1 \quad$ Study sites}

15 The study was undertaken at two shallow, eutrophic lakes in the UK (Fig. 1). Loch Leven is 16 the largest lake $\left(13.3 \mathrm{~km}^{2}\right)$ in lowland Scotland $\left(56^{\circ} 12^{\prime} \mathrm{N}, 3^{\circ} 22^{\prime} \mathrm{W}\right)$ with a mean depth of 3.9

17 m. Loch Leven water quality has been adversely affected by nutrients from domestic,

18 agricultural and industrial sources and, while there is some evidence for recovery (Carvalho

19 \& Kirika, 2003; Ferguson et al., 2008), cyanobacterial blooms continue to occur during

20 summer months. These blooms are typically dominated by genera such as Anabaena,

21 Microcystis, Snowella and Woronichinia. Esthwaite Water is a small lake in the English

22 Lake District $\left(54^{\circ} 21^{\prime} \mathrm{N}, 3^{\circ} 0^{\prime} \mathrm{W}\right)$ with a mean depth of $6.4 \mathrm{~m}$. The lake receives nutrients from

23 a local sewage treatment works and a fish farm. Cyanobacterial blooms dominated by genera

24 such as Anabaena, Aphanizomenon, Microcystis, Planktothrix and Woronichinia occur 
1 annually during the summer. Table 1 provides a summary of the physical and

2 physicochemical characteristics of the two lakes.

\subsection{Water sampling and analysis}

\subsubsection{Lake sampling for algorithm development and testing}

6 Water samples were collected from both lakes concurrrent with the airborne remote sensing

7 flights to provide ground reference data for algorithm development and testing. Five litre samples were collected from the surface using a large bucket at 5 stations across each lake.

9 The 5L water samples were thoroughly mixed to uniformly disperse any buoyant

10 cyanobacterial cells, and then split into replicate aliquots for phytoplankton cell counts and 11 pigment and microcystin analysis. The samples intended for phytoplankton counts were immediately fixed with Lugol's Iodine solution $(1 \% \mathrm{v} / \mathrm{v})$. Samples for pigment analysis were stored on ice in the dark for $<6 \mathrm{~h}$ before they were filtered by passing the sample through

14 replicate Whatman GF/F filters under vacuum pressure and freezing the filters at $-80^{\circ} \mathrm{C}$ until

15 further analysis could be performed. Samples for microcystin analysis were stored in the dark at $4{ }^{\circ} \mathrm{C}$ and processed within $48 \mathrm{~h}$.

\subsubsection{Phytoplankton cell counts}

19 The concentration of cyanobacterial cells was determined in all the samples collected during the lake cruises. Cells were counted under an inverted microscope according to standard procedures (Brierley et al., 2007) with taxonomy following John et al. (2003). Biovolumes were calculated for the Loch Leven samples using appropriate geometric models for each taxon (Hillebrand et al., 1999). In addition, cell counts from routine fortnightly surveys were provided for both lakes by the Centre for Ecology \& Hydrology. 


\section{2.2.3. Pigment analysis}

2 Chl $a$ was extracted by manual grinding of filter discs for 1 min and soaking in $90 \%$ acetone

3 in the dark for $20 \mathrm{~h}$ at $-20^{\circ} \mathrm{C}$ \{ Hunter et al., 2008\}. The extracts were clarified by

4 centrifugation (10 $\mathrm{min}, 5000 \mathrm{x} g$ ) and the concentration of Chl $a$ was determined by

5 spectrophotometry using the equations of Lorenzen (1967). C-PC was extracted into a 50

$6 \mathrm{mmol} \mathrm{L} \mathrm{L}^{-1}$ sodium phosphate buffer ( $\mathrm{pH}$ 7.0) using probe ultrasonication ( 1 min in $15 \mathrm{~s}$ bursts)

7 and 9 consecutive freeze-thaw cycles $\left(-80\right.$ to $\left.4^{\circ} \mathrm{C}\right)$. This is a modification of the method

8 presented in Sarada et al. (1999) and was used here to increase extraction efficiency. The

9 extracts were clarified by centrifugation (10 $\mathrm{min}, 5000 \mathrm{x} \mathrm{g}$ ) and C-PC was determined by

10 spectrophotometry using the equations of Bennett and Bogorad (1973).

\subsubsection{Microcystin (MC) analysis}

13 MCs were analysed by enzyme-linked immunosorbent assay (ELISA) according to Metcalf et

14 al. (2000). The procedure included polyclonal antibodies raised against the commonly-

15 occurring MC structural variant, MC-LR, which show similar cross-reactivities with all other

16 MC variants tested, e.g. MC-LY, -LA and -LW. The ELISA was calibrated with purified

17 MC-LR and MC concentrations expressed as microcystin-LR equivalents. Environmental samples were analysed by ELISA either directly to determine extracellular (dissolved) MCs only, or after boiling in a waterbath at $100^{\circ} \mathrm{C}$ for one minute to release MCs from the

20 cyanobacterial cells (Metcalf \& Codd, 2000). In the latter case, the MCs determined

21 comprised the soluble (extracellular) plus particulate (intracellular) toxin pools (Metcalf and

22 Codd, 2000), and are termed "total microcystin". Analysis of all environmental samples for

23 MCs was performed in triplicate.

\subsection{Radiometric measurements}


1 Radiometric measurements were made concurrent to the airborne overflights so that the

2 accuracy of the atmospheric correction applied to the CASI-2 and AISA Eagle data could be

3 assessed. Shipboard measurements of downwelling $\left(E_{\mathrm{d}}\left(0^{+}, \lambda\right)\right)$ and water-leaving radiance

$4 \quad\left(L_{\mathrm{w}}(0+, \lambda)\right)$ just above the water surface were collected at the sampling stations using an ASD

5 FieldSpec HandHeld VNIR (Analytical Spectral Devices Inc., Boulder, CO) spectrometer.

6 The ASD FieldSpec instrument has a spectral interval of $1.4 \mathrm{~nm}$ and a full-width half

7 maximum of $3 \mathrm{~nm}$ over the sampling range of 348-1074 $\mathrm{nm}$.

9 The instrument was mounted on a telescopic pole that was extended over the side of the 10 vessel at $0.5 \mathrm{~m}$ above the water surface to ensure that measurements were not affected by

11 shadows cast by the boat. The measurement geometry followed Mobley (1999) with spectra acquired at an approximate viewing zenith angle $=42^{\circ}$ and azimuth angle $=135^{\circ}$ over solar zenith angles $=42 \cdot 1-58 \cdot 1^{\circ}$. This measurement geometry was used to minimise the contribution of sky radiance $\left(L_{\mathrm{sky}}(0+, \lambda)\right)$ to $L_{\mathrm{w}}(0+, \lambda)$ and because the spectra were collected under clear skies and over turbid water the skylight effect would have been largely limited to the blue wavelengths that were not utilised this study. We therefore did not invoke a correction for the skylight term. $E_{\mathrm{d}}\left(0^{+}, \lambda\right)$ was obtained from a calibrated Spectralon reflectance panel. $R_{\mathrm{rs}}\left(0^{+}, \lambda\right)$ was calculated as the ratio of $L_{\mathrm{w}}(0+, \lambda)$ to $E_{\mathrm{d}}\left(0^{+}, \lambda\right)$.

\subsection{Remote sensing}

\subsubsection{Data acquisition}

The AISA Eagle and Hawk sensors were flown in tandem over Esthwaite Water and Loch Leven on the 13 and 26 April, 2007. CASI-2 was flown over Loch Leven on 22 August

24 2007. The overflights occurred between 10:00 and 14:00 h Greenwich Mean Time under 
$1 \quad\left(\right.$ field of view $\left.(\mathrm{FOV})=39.7^{\circ}\right)$ across 126 spectral pixels over the range $400-970 \mathrm{~nm}$ and a 2.9

$2 \mathrm{~nm}$ spectral resolution. The AISA Hawk is a 14-bit pushbroom hyperspectral sensor with a

3320 pixel swath width $\left(\mathrm{FOV}=24.0^{\circ}\right)$ across 237 spectral pixels over the range $970-2450 \mathrm{~nm}$

4 and an $8 \mathrm{~nm}$ spectral resolution. CASI-2 is a fully-customisable 12-bit pushbroom sensor.

5 CASI-2 was operated in Spatial Mode providing a 512 pixel swath width $\left(\mathrm{FOV}=54.4^{\circ}\right.$ ) and

612 spectral pixels. The channel configuration used for CASI-2 was optimised for the imaging

7 of Case 2 waters as described by Hunter et al. (2008b).

9 The sensors were flown on a Dornier 228-101 fixed wing airplane at an altitude between

$10 \quad 2900-3200 \mathrm{~m}$ (above ground level) and at a ground speed of $135 \mathrm{knots}(250 \mathrm{kph})$. The

11 resulting AISA Eagle and Hawk imagery had spatial resolutions (at nadir) of between 2.0-2.1

$\mathrm{m}$ and 3.6-3.9 $\mathrm{m}$ respectively and the CASI-2 imagery had a spatial resolution of approximately $6 \mathrm{~m}$. The imagery was flown in a south-to-north direction over Esthwaite and a southeast-to-northwest direction over Loch Leven to minimise sun glint effects. Four separate flightlines with an overlap of approximately $30 \%$ were flown over Loch Leven and mosaicked together to achieve full lake coverage. The aircraft turn time between flightlines was typically less than 5 min.

\subsubsection{Geometric and atmospheric correction}

The airborne imagery was geometrically corrected for pitch, roll and yaw effects using the azgcorr programme and geolocated using navigation data obtained by a differentiation global position system. The individual AISA Eagle and Hawk bandsets were mosaicked together using coordinate based layer stacking. The AISA Eagle and Hawk at-sensor radiances were

24 atmospherically corrected to $R_{\mathrm{rs}}\left(0^{+}, \lambda\right)$ using the Fast Line-of-Sight Atmospheric Analysis of Spectral Hypercubes (FLAASH) module in RSI ENVI (v.4.5). FLAASH is a physics-based 
1 atmospheric correction model developed by Spectral Sciences Incorporated (Alder-Golden et

2 al., 1999) and based upon the widely-used and well-validated MODTRAN4 (MODerate

3 resolution atmospheric TRANsmission) radiative transfer code. FLAASH has been used

4 successfully in previous research for the atmospheric correction of hyperspectral data

$5 \quad$ Kutser, 2004; Cooley et al. 2002\}.

6

7 The inputs into FLAASH comprised the altitude of the sensor, the ground elevation above sea

8 level, the pixel size of the imagery and the flight date and time. The atmospheric model used

9 was the MODTRAN4 Sub-Arctic. The concentration of aerosols was retrieved on a pixel-by-

10 pixel basis according to the 2-band (K-T) method of Kaufman et al. (1997) using a rural

11 model and the AISA Hawk channels located at 660 and $2100 \mathrm{~nm}$, and 420 and $800 \mathrm{~nm}$.

12 Water vapour was retrieved pixel-by-pixel using the water absorption feature located at 1135

$13 \mathrm{~nm}$. The AISA Eagle spectra were interpolated to a final resolution of $0.5 \mathrm{~nm}$ and the

14 accuracy of the atmospheric correction was assessed by checking for quantitative agreement

15 with the $R_{\mathrm{rs}}\left(0^{+}, \lambda\right)$ spectra calculated from the in-situ radiometry. The accuracy of the atmospheric correction was assessed on the basis of the root mean square error (RMSE).

It was not possible to correct the CASI-2 data using FLAASH because the sensor does not possess channels in the near- and mid-infrared needed for aerosol and water vapour retrieval.

20 In addition, because FLAASH only models the atmosphere for a single nadir looking direction, it does not account for the increase in path length that occurs in the cross-track direction for wide FOV sensors such as CASI-2. We therefore used the empirical line technique $\{$ Karpouzli and Malthus, 2003\} to convert the CASI-2 at-sensor radiances to approximate $R_{\mathrm{rs}}\left(0^{+}, \lambda\right)$. 


\subsection{Development and testing of inversion algorithms}

We tested the semi-analytical algorithms of Gons (1999) and Dall'Olmo et al. (2003) for the retrieval of Chl $a$ and of Simis et al. (2005), and a modified version of Dall'Olmo et al. (2003), for the retrieval of C-PC. The algorithms of Gons (1999) and Simis et al. (2005) estimate the values of $a_{\mathrm{chl}}(665)$ and $a_{\mathrm{CPC}}(620)$ respectively; the values for $a_{\mathrm{chl}}(665)$ and $a_{\mathrm{CPC}}(620)$ were converted to pigment concentrations by dividing by the specific absorption coefficients for Chl $a$ at $665 \mathrm{~nm}\left(0.0153 \mathrm{~m}^{-1}\right)$ and C-PC at $620 \mathrm{~nm}\left(0.007 \mathrm{~m}^{-1}\right)$ as given in Simis et al. (2007).

The wavelengths used in the medium-independent algorithm developed by Dall'Olmo et al (2003) can be spectrally-tuned to optimise Chl $a$ retrieval. In this study, we adopted the parameterisation of the algorithm used by Gitelson et al. (2008) for MERIS-like sensors:

$$
\text { Chl } a=23.1+117.4 \times\left\{\left[R_{\mathrm{rs}}^{-1}(600-670)-R_{\mathrm{rs}}^{-1}(700-730)\right] \times R_{\mathrm{rs}}(740-760)\right\}
$$

We did not re-optimise the algorithm for the retrieval of Chl $a$ so that we could test its ability for generalisation.

In addition, we adapted the algorithm of Dall'Olmo et al. (2003) for estimating C-PC. Here, it was necessary to optimise the wavelengths and coefficients used for C-PC retrieval. This was achieved by initially setting $\lambda_{1}=620 \mathrm{~nm}$ (C-PC absorption maximum) and $\lambda_{3}=730 \mathrm{~nm}$ and then regressing the model $\left[R_{\mathrm{r}}^{-} \zeta^{\prime} 620-R_{\mathrm{r}}^{-}\left(\lambda_{2}\right)\right\}: R_{\mathrm{r}}(7330$ against the measured concentration of C-PC for values of $\lambda_{2}$ between 560 and $660 \mathrm{~nm}$. In the second iteration, $\lambda_{2}$ was set to $600 \mathrm{~nm}$ and then the model $\left[R_{\mathrm{r}}^{-} \zeta^{1} 620-R_{\mathrm{r}}^{-} \oint^{-} 6000\right]: R_{\mathrm{r}}\left(\lambda_{3}\right)$ was regressed against the measured concentrations of Chl $a$ for values of $\lambda_{3}$ between 700 and $775 \mathrm{~nm}$. In the final 
1 iteration, $\lambda_{3}$ was set to $725 \mathrm{~nm}$ and $\lambda_{1}$ was optimised by regressing the model

$2\left[R_{\mathrm{r}}^{-}\left(\lambda_{1}\right)-R_{\mathrm{r}}^{-}{ }^{1} 6000\right\}$ K $R_{\mathrm{r}}(725)$ against the measured concentrations of Chl $a$ for values of $\lambda_{1}$

3 between 610 and $630 \mathrm{~nm}$. This resulted in the following algorithm for C-PC retrieval:

4

5

6

7 The wavelengths used in Eq. 10 differ somewhat from those originally employed for the 8

$$
\mathrm{CPC} \propto\left[R_{\mathrm{rs}}^{-1}(615)-R_{\mathrm{rs}}^{-1}(600)\right] \times R_{\mathrm{rs}}(725)
$$

retrieval of C-PC by Hunter et al. (2008a) $\left(\lambda_{1}=630 ; \lambda_{2}=660 ; \lambda_{3}=750\right)$. This is mostly

likely because the $R_{\mathrm{rs}}\left(0_{+}, \lambda\right)$ made in Hunter et al. (2008a) were made from laboratory cultures of cyanobacteria.

To evaluate the performance of the algorithms proposed by Gons (1999), Simis et al. (2005) and Dall'Olmo et al. (2003), we developed a number of semi-empirical algorithms for the retrieval of Chl $a$ and C-PC that were optimised for our study lakes. We used the band-ratios $\left[R_{\mathrm{rs}}(705): R_{\mathrm{rs}}(670)\right]$ and $\left[R_{\mathrm{rs}}(705): R_{\mathrm{rs}}(620)\right]$ for the estimation of Chl $a$ and C-PC respectively because these indices have been used effectively in previous research (Hunter et al., 2008b, 2009). The semi-empirical algorithms were derived by regressing the band-ratios against the measured concentrations of $\mathrm{Chl} a$ and C-PC. In addition, we derived a further algorithm for the retrieval of C-PC by incorporating both the $\left[R_{\mathrm{rs}}(705): R_{\mathrm{rs}}(620)\right]$ and $\left[R_{\mathrm{rs}}(705): R_{\mathrm{rs}}(670)\right]$ band-ratios in a multivariate regression model. It was anticipated that this might provide a rudimentary correction for the effect of Chl $a$ absorption on the retrieval of C-PC.

The performance of the inversion algorithms was assessed on the basis of the coefficient of determination $\left(\mathrm{R}^{2}\right)$ and the root mean square error (RMSE) derived comparison with the measured pigment concentrations. Subsequently, the retrieved concentrations of Chl $a$ and 
1 C-PC from the best-performing algorithms were compared to cyanobacterial cell counts and

2 measured $\mathrm{MC}$ concentrations by regression analysis.

\section{3. Results and discussion}

\subsection{Cyanobacterial cells, pigments and toxins}

6 The seasonal change in the abundance of cyanobacteria in Esthwaite Water and Loch Leven

7 is shown in Fig. 2 and a summary of the pigment and cell concentrations measured in the

8 lakes concurrent to the airborne overflights is presented in Table 2. The AISA Eagle data

9 collected over Loch Leven on 13 Apr coincided with the end of the spring diatom bloom and

10 the beginning of the clear water phase. The abundance of cyanobacteria at this time was very

11 low (approximately 26 cells $\mathrm{cm}^{-3}$ ). The mean concentrations of $\mathrm{Chl} a$ and C-PC were

12 consequently also low at 6.58 and $1.15 \mathrm{mg} \mathrm{m}^{-3}$ respectively and C-PC:Chl $a$ ratio was 0.175 .

14 The AISA Eagle data acquired on 26 Apr over Esthwaite Water coincided with the early 15 stages of a bloom of the potentially-toxic cyanobacterium Anabaena circinalis. The mean 16 concentration of cyanobacteria measured in the lake on 26 Apr was approximately 18767

17 cells $\mathrm{cm}^{-3}$, but this varied considerably among the various sampling stations. The mean 18 concentrations of $\mathrm{Chl} a$ and C-PC were 10.4 and $16.8 \mathrm{mg} \mathrm{m}^{-3}$ respectively; the C-PC:Chl $a$ 19 ratio was 1.62 which suggests cyanobacterial dominance (Simis et al., 2005).

21 The CASI-2 flights over Loch Leven on 22 Aug also coincided with a cyanobacterial bloom: in this instance co-dominated by Aphanothece spp., Woronichinia naegeliana and, to a lesser extent, Microcystis aeruginosa. The mean concentration of cyanobacteria on 22 Aug was 25

24238 cells $\mathrm{ml}^{-1}$, but again this varied considerably between sampling stations. The mean 
1 concentrations of $\mathrm{Chl} a$ and C-PC were 36.3 and $68.9 \mathrm{mg} \mathrm{m}^{-3}$ respectively and the C-PC:Chl

$2 a$ ratio was 1.90 , which again strongly indicates cyanobacterial dominance.

4 Microcystins were detected by ELISA in both lakes (Fig. 3). Confirmation of the toxins was

5 provided by high performance liquid chromatography with photodiode array detection

6 (Metcalf et al., 2000). This yielded characteristic peaks (abs. max. $238 \mathrm{~nm}$ ) of multiple MC

7 variants (data not shown). In all instances, the total concentration of MCs measured in the

8 two waterbodies exceeded the current guideline value of $1 \mathrm{mg} \mathrm{m}^{-3} \mathrm{MC}-\mathrm{LR}$ in drinking water

9 established by the World Health Organisation (WHO) (WHO, 2002, 2003) and were thus of

10 significance for human health. The lowest mean concentration of total MCs was measured in

11 Loch Leven on 13 Apr and the highest mean concentration was measured in the same lake

12 during the cyanobacterial bloom on 22 Aug. The MCs occurred in dissolved form in the

13 water phase and in the cyanobacteria-containing particulate fraction. The \% distribution

14 between these pools varied widely (Fig. 3) from being almost entirely soluble (mean 94\% :

15 Loch Leven, April) to being almost entirely particulate (mean 96\% : Loch Leven, August).

17 This variability in MC compartmentation has implications for the use of remote sensing as a

18 tool for aiding risk assessment activities for human health protection. It is not possible to

19 detect dissolved MCs directly by remote sensing. The concentration of cyanobacterial cells

20 within a MC-producing bloom can, however, be used as an indicator of potential MC

21 concentrations. The implicit assumptions are that (i) the MC pool is predominantly

22 intracellular and (ii) MC concentrations per cell are relatively uniform within and between

23 blooms. If a substantial proportion of the total MC pool occurs in the soluble phase, or where

24 environmental conditions influence intracellular MC pool sizes, then it cannot necessarily be 
1 assumed that remotely sensed estimates of cyanobacterial cell biomass will provide a reliable measure of bloom MC concentrations.

4 The largely extracellular proportion (ca. 94\%) of the total MC pool detected in Loch Leven

5 may have included an over-winter residual of the MCs released during the decline of the

6 cyanobacterial bloom in the previous autumn. This possibility is raised because: (i) the

7 residence time in Loch Leven is ca. 180 days (Table 1); (ii) although MCs are susceptible to

8 microbial degradation in water, biodegradation rates are temperature-dependent and minimal

9 in winter (Ward, 1999). The very low concentrations of cyanobacterial cells and C-PC

10 measured in Esthwaite on 13 Apr would therefore not have provided a sentinel indication of

11 potential risks to health because of this dissolved MC pool.

\subsection{Atmospheric correction}

14 The AISA Eagle $R_{\mathrm{rs}}\left(0^{+}, \lambda\right)$ spectra calculated by the FLAASH atmospheric correction model

15 were realistic for Case 2 waters in terms of their shape and magnitude and they demonstrated

16 a reasonable level of correspondence with the in-situ $R_{\mathrm{rs}}\left(0^{+}, \lambda\right)$ spectra. The $R_{\mathrm{rs}}\left(0^{+}, \lambda\right)$ spectrum calculated by FLAASH and that measured near to Station 01 on Esthwaite Water during the overflights on $26 \mathrm{Apr}$ is shown in Fig. 4. The shape of the $R_{\mathrm{rs}}\left(0^{+}, \lambda\right)$ spectrum calculated by FLAASH closely resembles that measured in-situ and the reflectance troughs associated with the Chl $a$ and C-PC absorption peaks have been clearly preserved. Moreover, the FLAASH calculated spectrum mainly lies within the $95 \%$ confidence interval for mean in-situ $R_{\mathrm{rs}}\left(0^{+}, \lambda\right)$.

24 The RMSE of $R_{\mathrm{rs}}\left(0^{+}, \lambda\right)$ calculated by FLAASH from the AISA Eagle data for all stations on 
1 RMSE(\%) of between 26.4 and $77.7 \%)$. The RMSE on the values of $R_{\mathrm{rs}}\left(0^{+}, \lambda\right)$ calculated by

2 FLAASH from the AISA Eagle data from Esthwaite Water on 26 Apr ranged from 0.00369

3 to 0.0114 (400 to $800 \mathrm{~nm}$ ) (equating to a RMSE(\%) of between 19.7 and $141.9 \%$ ).

5 Correspondence between reflectance measured in-situ and from the aircraft was strongly

6 wavelength-dependent and generally strongest in the green, red and on the NIR shoulder

$7 \quad(520-720 \mathrm{~nm})$ and poorest in the blue $(<500 \mathrm{~nm})$ and at NIR wavelengths beyond $750 \mathrm{~nm}$.

8 The relatively large uncertainties observed in the blue region were partly due to the poorer

9 radiometric calibration of the AISA Eagle sensor and strong aerosol and water vapour

10 scattering. The degree of correspondence also deteriorated significantly with the time

11 elapsed between the overflights and the in-situ sampling (Fig. 5).

13 The empirical line correction applied to the CASI-2 data yielded coefficients of determination

14 for the regression equations between $R^{2}=0.76$ and 0.99 for the 13 channels (see Table 3 ).

15 The accuracy of empirical line correction was generally better for the channels centred at red

16 and near-infrared wavelengths used in the semi-empirical and semi-analytical algorithms

17 pigment retrieval $\left(\mathrm{R}^{2}=0.86-0.98\right)$.

\subsection{Retrieval of Chl a}

20 The relationship between the measured concentrations of Chl $a$ and the $\left[R_{\mathrm{rs}}(710): R_{\mathrm{rs}}(670)\right]$

21 band-ratio was strongly non-linear. The two best-performing semi-empirical algorithms for the retrieval of Chl $a$ were derived using quadratic functions of the $\left[R_{\mathrm{rs}}(710): R_{\mathrm{rs}}(670)\right]$ bandratio. The inversion algorithm employing the decadic $\log$ of $\mathrm{Chl} a$ as the response variable

24 provided the marginally better estimation $\left(\mathrm{R}^{2}=0.856\right.$; $\left.\mathrm{RMSE}=5.29 \mathrm{mg} \mathrm{m}^{-3}\right)$ (see Table 4).

25 This algorithm markedly outperformed the semi-empirical algorithms based upon linear 
1 functions of $\left[R_{\mathrm{rs}}(710): R_{\mathrm{rs}}(670)\right]$ and also performed better than the semi-analytical algorithm

2 of Dall'Olmo et al. (2003).

4 The Dall'Olmo et al. (2003) algorithm did provide reasonable estimates of Chl $a$ when 5 applied to the data acquired over Esthwaite Water on 26 Apr and the CASI-2 data acquired 6 over Loch Leven on $22 \operatorname{Aug}\left(\mathrm{R}^{2}=0.796\right.$; RMSE $\left.=9.92 \mathrm{mg} \mathrm{m}^{-3}(44.5 \%)\right)$. However, the 7 algorithm greatly underestimated the concentrations of Chl $a$ measured in Loch Leven on 13 $8 \operatorname{Apr}\left(\mathrm{R}^{2}=0.019 ; \mathrm{RMSE}=35.6 \mathrm{mg} \mathrm{m}^{-3}(541 \%)\right)$. The reasons for this are not entirely clear.

9 The algorithm is not based upon a ratio of $R_{\mathrm{rs}}(\lambda, 0+)$ and is thus likely to be more sensitive to 10 shifts in the amplitude of the water-leaving signal. The comparatively low phytoplankton biomass in Loch Leven in early April would certainly have enhanced the contributions from non-phytoplankton particles and bottom reflectance to the water-leaving signal. In addition, the atmospheric correction of the AISA Eagle data from 13 Apr was poorer than that achieved for the other datasets. These factors could have produced shifts in spectral amplitude sufficient to impair algorithm performance.

The values retrieved using the algorithm of Gons (1999) were very strongly correlated with the measured concentrations of Chl $a\left(\mathrm{R}^{2}=0.879\right)$ (see Fig. 6). However, the algorithm tended to overestimate the actual concentrations of Chl $a$ and consequently the RMSE was larger $\left(22.6 \mathrm{mg} \mathrm{m}^{-3}\right)$ than that returned by the best-performing semi-empirical algorithm. The over-estimation of Chl $a$ by the Gons (1999) algorithm might have been the result of using an inappropriate value of $\boldsymbol{a g}_{\mathbf{Q}}^{*} \mathbf{6}$, , rather than errors in the estimation of S. We did not determine $\stackrel{*}{a}\left(G_{2}\right)($ in this study. Instead, we used the value measured by Simis et al. (2005). However, $a_{c}^{*}(2)$ can vary in response to changes in pigment composition and packaging, which is similarly dependent on the physiological status, size 
1 spectra and floristic composition of the phytoplankton community (Bricaud et al., 1995, , 2 2004).

4 Simis et al. (2005) found that $\stackrel{*}{*}(\mathbf{6})$ e varied between 0.0138 and $0.0203 \mathrm{~m}^{-1}$ in Lake

5 Ijsselmeer in the Netherlands. The substitution of $\underset{\alpha}{*}(\mathbf{G}) C=0.0203 \mathrm{~m}^{-1}$ into the Gons 6 (1999) algorithm was sufficient to reduce the RMSE for the estimation of Chl $a$ in Eshtwaite 7 Water and Loch Leven to $11.9 \mathrm{mg} \mathrm{m}^{-3}(41.4 \%)$. This not only emphasises the extent to which $8 a_{c}^{*}$ (2) can vary, but also why it is important to make rigorous measurements of the specific

9 inherent optical properties of waterbodies so that analytically-based algorithms can be 10 properly parameterised for constituent retrieval. There is a clear need for more detailed 11 studies of the inherent optical properties of inland waterbodies to support algorithm 12 development and testing.

14 This issue notwithstanding, the coefficients estimated by the semi-analytical algorithm of Gons (1999) were as strongly correlated with the measured concentrations of Chl $a$ as the band-ratios employed in the semi-empirical inversion algorithms. This is

17 perhaps somewhat surprising given that the semi-empirical algorithms were optimised using 18 these specific datasets. It is considered that semi-analytical algorithms are more transferable across different water types. The fact that the accuracy of the semi-analytical algorithms is shown here to be comparable to that achievable with optimised semi-empirical models merely strengthens the case for the wider use of analytical approaches for the retrieval of inwater constituents. However, while analytical algorithms are widely used for Chl $a$ retrieval 23 in coastal and ocean waters, they have yet to be widely tested in inland waters. This is a clear 24 priority for future research. 


\subsection{Retrieval of $C-P C$}

2 The best performing semi-empirical algorithm for the retrieval of C-PC was developed using 3 a quadratic model based on the $\left[R_{\mathrm{rs}}(710): R_{\mathrm{rs}}(620)\right]$ band-ratio $\left(\mathrm{R}^{2}=0.982 ; \mathrm{RMSE}=4.00 \mathrm{mg}\right.$ $4 \mathrm{~m}^{-3}(13.8 \%)$ ) (Table 5). However, all the semi-empirical algorithms for the retrieval of C-PC 5 returned estimates of C-PC with $\mathrm{R}^{2}$ values $>0.86$ and $\mathrm{RMSEs}<10.5 \mathrm{mg} \mathrm{m}^{-3}$. Interestingly,

6 the multivariate regression model incorporating both the $\left[R_{\mathrm{rs}}(710): R_{\mathrm{rs}}(620)\right]$ and

$7 \quad\left[R_{\mathrm{rs}}(710): R_{\mathrm{rs}}(670)\right]$ band-ratios provided a better estimation of C-PC $\left(\mathrm{R}^{2}\right.$ adj. $=0.935 ; \mathrm{RMSE}$

$8=7.13(24.6))$ than the model using only the $\left[R_{\mathrm{rs}}(710): R_{\mathrm{rs}}(620)\right]$ band-ratio $\left(\mathrm{R}^{2}=0.907\right.$;

$9 \quad \operatorname{RMSE}=9.22(31.8))$. This suggests that the incorporation of the $\left[R_{\mathrm{rs}}(710): R_{\mathrm{rs}}(670)\right]$ band-

10 ratio was partly effective in providing a rudimentary correction for Chl $a$ absorption at 620

$11 \mathrm{~nm}$. However, clearly it might not be possible to generalise this type of empirical correction to other waterbodies beyond those considered here.

14 The values of $a_{\mathrm{CPC}}(620)$ estimated by the algorithm of Simis et al. (2005) were strongly

15 correlated with the measured concentration of C-PC $\left(\mathrm{R}^{2}=0.984\right)$ and the resulting concentrations of C-PC derived from these coefficients also demonstrated a near 1:1 relationship with measured C-PC values $\left(\mathrm{RMSE}=3.98 \mathrm{mg} \mathrm{m}^{-3}(13.7 \%)\right.$ ) ( Fig. 6). The accuracy of C-PC retrieval provided by the Simis et al. (2005) algorithm was superior to that achieved by the semi-empirical inversion algorithms.

21 The semi-analytical algorithm based upon the model proposed by Dall'Olmo et al. (2003) for the retrieval of Chl $a$ also performed strongly $\left(\mathrm{R}^{2}=0.921 ; \mathrm{RMSE}=2.65 \mathrm{mg} \mathrm{m}^{-3}(9.15 \%)\right)$

23 when applied to the dataset collected over Loch Leven on 13 Apr and Esthwaite Water on 26

24 Apr. We could not apply this algorithm to the CASI-2 dataset acquired over Loch Leven on 22 Aug because of the incompatible channel configuration. The Simis et al. (2005) algorithm 
1 was not particularly sensitive to the uncertainties in atmospheric correction in spite of the fact

2 that it uses an absolute value of $R_{\mathrm{rs}}(0+, \lambda)$ to estimate the $b_{b}(779)$ coefficient and has

3 previously been shown to be sensitive to shifts in spectral amplitude (Ruiz-Verdu et al.,

4 2008). However, it is likely that the any errors in the estimation of $b_{b}(779)$ are relatively

5 insignificant at high C-PC concentrations.

6

7 The superior performance of the Simis et al. (2005) algorithm is almost certainly attributable

8 to the fact that it corrects for the contribution of $\mathrm{Chl} a$ to absorption at $620 \mathrm{~nm}$. The relative

9 contribution of $\mathrm{Chl} a$ to absorption at $620 \mathrm{~nm}$ is obviously strongly dependent on the floristic

10 composition of the phytoplankton community and, more specifically, on the abundance of

11 cyanobacteria containing C-PC. The relative contribution of Chl $a$ to total pigment

12 absorption at $620 \mathrm{~nm}$ can thus be expected to be inversely proportional to C-PC:Chl $a$. The

13 contribution of $\mathrm{Chl} a$ is relatively insignificant in waters with high C-PC:Chl $a$ ratios.

14 However, in waters with low C-PC:Chl $a$ ratios, the increased contribution of Chl $a$ to total

15 absorption at $620 \mathrm{~nm}$ is known to lead to errors on the estimation of C-PC (Simis et al.,

16 2007). We found that the value of the relative residuals increases significantly at C-PC:Chl $a$

$17 \leq 0.5$ (Fig. 7), in agreement with findings reported elsewhere (Ruiz-Verdu et al., 2008;

18 Randolph et al., 2008; Hunter et al., 2008b).

19

20 The cell counts made at Esthwaite Water and Loch Leven suggest that C-PC:Chl $a=0.5$ is

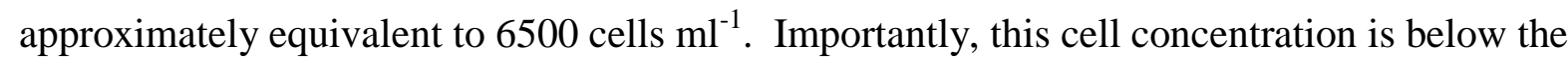
WHO health guidance values for cyanobacteria cell numbers in recreational waters. This is significant because it suggests that this algorithm (and the best-performing semi-empirical

24 algorithms) can detect cyanobacterial cells at concentrations significantly below those at 25 which they would typically pose risks to human health by recreational contact and ingestion. 
1 This emphasises the fact that remote sensing has the potential to provide early-warnings of

2 cyanobacterial bloom development (Hunter et al., 2009).

\subsection{Comparisons between cyanobacterial cells, pigments and microcystins}

5 The C-PC estimates retrieved using the algorithm of Simis et al. (2005) were weakly, but

6 significantly, related to the concentration of cyanobacterial cells $\left(R^{2}=0.380 ; p=0.014\right)$ (Fig.

7 8a). The retrieved concentrations of C-PC were also significantly correlated with

8 cyanobacterial biovolume as measured in the samples from Loch Leven $\left(\mathrm{R}^{2}=0.483 ; \mathrm{p}=\right.$

9 0.026) (no biovolume estimates were available for Esthwaite Water). The retrieved estimates

10 of Chl $a$ were not significantly correlated with either cyanobacterial cell numbers or

11 biovolume.

13 The relationship between cyanobacterial cell concentration and that of the C-PC biomarker

14 pigment was notably weaker than those previously reported elsewhere (e.g. Brient et al.,

15 2008; Randolph et al., 2008). It is possible that some of the scatter in this relationship might

16 be simply explained by the uncertainties inherent in microscopic cell counts. However, the

17 intracellular concentration of C-PC is also known to be strongly dependent upon irradiance

18 and the supply of fixed nitrogen (Fogg et al., 1973; Jiang \& Qiu, 2005; Raps et al., 1983).

19 The relationship between cell and C-PC concentrations measured in the water column is

20 therefore likely to vary in response to seasonal patterns in both light and nutrient supply.

Intriguingly, in our case the majority of the scatter observed in the relationship between cell numbers and C-PC concentration was the result of within-lake spatial variation rather than seasonal (or between-lake) variation. This implies that C-PC cell quotas were highly variable within the individual blooms. This variability might reflect differences in water depth and 
1 circulation among the sampling stations which in turn is likely to have influenced the light

2 history (in terms of quality and quantity) of the cyanobacterial cells. That is, positively

3 buoyant cells stationed in shallow waters might have experienced significantly higher

4 irradiances compared to cells entrained within deeper vertically mixing waters.

6 Heterogeneity in the species composition of the blooms might also have contributed to scatter

7 in the cell-pigment relationship. Phycobiliprotein cell quotas can vary markedly across

8 different cyanobacteria (e.g. Patel et al., 2005). This is likely to cause variability in the

9 association between the concentrations of cells and pigments in the water column where

10 spatial distribution of species is not uniform. This is particularly likely to occur where

11 blooms are composed of both buoyancy-regulating and non-buoyancy-regulating species.

13 The Loch Leven bloom on 22 Aug contained both buoyancy-regulating (Microcystis,

14 Woronichinia) and non-buoyancy-regulating genera (Aphanothece). These differing traits

15 might have led to variability in their distribution throughout Loch Leven and consequently

16 influenced the correlation between cell numbers and pigment concentrations. That said, the

17 bloom on Esthwaite Water on 22 Apr was almost entirely dominated by Anabaena: thus

18 variability in species composition cannot be used to explain the lack of a strong correlation

19 between cells and pigments in this instance.

21 The relationship between the concentration of cyanobacterial cells and total MCs was also

22 weak and only just significant $\left(\mathrm{R}^{2}=0.251 ; \mathrm{p}=0.057\right)$. This can be partly explained by the

23 fact that MC production is influenced to some extent by nutrient supply and environmental

24 conditions. Cellular MC content has been shown to correlate positively with nutrient supply

25 and to decrease at high irradiances (Rapala et al., 1997; Wiedner et al., 2003). The accessory 
1 phycobiliproteins and MCs thus appear to respond in similar ways to variations in resource

2 supply. Therefore, it is perhaps not surprising that the retrieved concentrations of C-PC in

3 Esthwaite Water and Loch Leven were very strongly correlated with the concentrations of

4 particulate $\left(\mathrm{R}^{2}=0.906 ; \mathrm{p}=<0.0005\right)$ and total MCs $\left(\mathrm{R}^{2}=0.896 ; \mathrm{p}=<0.0005\right)($ Fig. $8 \mathrm{~b})$.

5 Strong correlations between the phycobiliprotein and MC content of cyanobacteria have also

6 been reported elsewhere (e.g. Izydorczyk et al., 2005). Chl $a$ was less strongly correlated

7 with total MCs $\left(\mathrm{R}^{2}=0.665 ; \mathrm{p}=<0.0005\right)$. These observations imply that the $\mathrm{C}-\mathrm{PC}$ content

8 of cells might provide a crude measure of bloom MC content (assuming that MC-producing

9 strains are present).

$113.6 \quad$ Monitoring cyanobacterial populations in lakes

12 Information on the presence and abundance of cyanobacteria in lakes is needed to (i) feed

13 into local, regional and national monitoring activities such as those required under the EU

14 WFD; (ii) provide intelligence to support risk assessment activities to protect human health

15 from toxin-producing blooms; (iii) provide essential information on ecosystem processes and

16 function. However, standard lake monitoring programmes are currently constrained by an

17 inability to obtain this information at high spatial and temporal resolutions. Sampling at a

18 single or a small number of stations will rarely provide a representative estimate of

19 cyanobacterial abundance where blooms are distributed patchily across lakes. Moreover,

20 since blooms can increase and decrease over relatively short time scales (e.g., days to weeks),

21 samples collected on a fortnightly or monthly basis are unlikely to trace the underlying dynamism of cyanobacterial populations in lakes.

24 Mounting concerns about the pressures impacting aquatic ecosystems mean that the

25 development of more effective and efficient monitoring systems is becoming an ever- 
1 increasing priority. In Europe, the WFD has placed an increased burden on those agencies

2 responsible for monitoring, assessing and managing the ecological status of Europe's surface

3 waters. The metrics being considered for the assessment of lake ecological status include Chl

$4 a$ concentration and cyanobacterial biomass. It has been widely shown that $\mathrm{Chl} a$ can be

5 estimated relatively reliably in inland waters using remotely sensed data (Kutser, 2004; Tyler

6 et al., 2006; Gons et al., 2008). This study and others also now show that cyanobacterial

7 biomass estimation by remote sensing is achievable (Simis et al., 2007; Ruiz-Verdu et al.,

8 2008; Randolph et al., 2008). Remote sensing-based estimates of phytoplankton biomass

9 could thus strongly contribute to regulatory monitoring of surface water ecological status

10 under the WFD, although operational capability is currently restricted to larger lake systems

11 observable from ocean colour platforms.

13 The remotely-sensed estimation of cyanobacterial biomass could also be used to support

14 hazard recognition and risk assessments activities for the protection of human and animal

15 health. It has been shown that remotely sensed information can be integrated with existing

16 alert monitoring protocols such as the WHO guideline levels (GLs) for recreational waters to

17 aid the assessment of human health risks (Hunter et al., 2009). The WHO GLs for

recreational waters indicate that cyanobacterial cell concentrations of $\geq 20000$ and $\geq 100$

000 cells $\mathrm{ml}^{-1}$ equate to low and moderate risks respectively of adverse health effects in

20 humans, while the presence of cyanobacterial scums is considered to pose the highest risks to

21 human health. Significantly, we have demonstrated that cyanobacterial populations can be detected using remote sensing at levels well below those currently used to provide human

23 health warnings. The use of remote sensing platforms for the early-warning of cyanobacterial

24 blooms in lakes and other waterbodies for health protection would therefore seem to be

25 feasible. 
2 The value of using remotely sensed imagery to map cyanobacterial populations and provide

3 intelligence for health protection is clearly shown in Figs. 9 and 10. These mapped C-PC

4 image products show that the distribution of cyanobacterial cells in Esthwaite Water and

5 Loch Leven was very patchy with thick surface scums clearly visible on both lakes. This

6 patchiness was almost certainly caused by buoyant cyanobactria becoming entrained within

7 advective currents and massing as scums on windward shorelines (Hunter et al., 2008b). The

8 heterogeneous and transient nature of these scums complicates their detection in the field and

9 this can affect the assessment of health risks.

11 In spite of the fact that thick scums had formed elsewhere on both lakes, cyanobacterial cell 12 concentrations in the water samples collected from the sampling stations on Esthwaite Water 13 and Loch Leven never exceeded 100000 cells per ml (i.e. the WHO GL for moderate risk).

14 However, the scums recognised in the AISA Eagle and CASI-2 imagery are evidence of 15 much greater risks to human health. This is also supported by the measured concentrations of 16 MCs in these waterbodies. This highlights the extent to which limited sampling at discrete 17 stations in a heterogeneous waterbody may provide inadequate warning of the risks to health.

19 Spatially synoptic intelligence provided by remote sensing platforms, particularly with the 20 possibility of near real-time reporting, may overcome the limitations of heterogeneity and 21 point sampling (cloud cover permitting). Indeed, the next generation of high spatial and spectral resolution satellite-based imaging spectrometers, such as the German-led

23 Environmental Mapping and Analysis Program (EnMAP), will offer new opportunities for 24 monitoring phytoplankton populations in much smaller waterbodies. 
1 The inversion algorithms currently used for the retrieval of constituent concentrations in Case

22 waters were designed primarily for application with multispectral ocean colour sensors. To

3 exploit fully the hyperspectral capabilities of the new generation of spaceborne imaging

4 spectrometers it will be necessary to develop new and better approaches to the inversion of

5 water-leaving optical signals. In this respect, there is clearly a need for further work on the

6 development and testing of inversion algorithms for inland (and coastal) Case 2 type waters.

7

\section{4. Conclusions}

9 The accuracy of different semi-empirical and semi-analytical inversion algorithms for the

10 retrieval of Chl $a$ and C-PC was examined using high-resolution and multi-temporal AISA

11 Eagle and CASI-2 imagery from two shallow lakes in the UK. The best performing algorithm for the retrieval of Chl $a$ was a nonlinear semi-empirical model. The absorption coefficients returned by the semi-analytical algorithm of Gons (1999) were also strongly correlated with the measured pigment concentrations, but the actual retrieved pigment concentrations were subject to significant errors. These were mostly likely due to variability in the specific absorption coefficient of chlorophyll and as such the algorithm could easily be modified to reduce these uncertainties. The best performing inversion algorithm for the retrieval of C-PC was the semi-analytical nested band ratio algorithm of Simis et al. (2005). The absorption coefficients and actual C-PC concentrations returned by this algorithm were strongly correlated with those measured in the water samples collected from the lake. These results demonstrate that the performance of analytically-based algorithms is equal or superior to that of widely used semi-empirical approaches. The greater transferability of the analytical models also makes them better suited to regional or global scale monitoring of phytoplankton

24 pigments in lakes. These results strongly suggest that remotely sensed data might contribute significantly to the proactive and regulatory monitoring of lakes. 
2 The concentrations of C-PC retrieved using the semi-analytical nested band ratio algorithm

3 were correlated (albeit weakly) with cyanobacterial cell numbers and biovolume. Very

4 strong correlations were observed between the estimated C-PC concentrations and the

5 measured concentration of MCs. This implies that C-PC concentrations retrieved from

6 remotely sensed data might provide a useful indication of the potential risks to human health.

7 The ability to map cyanobacterial populations at a synoptic scale and recognise the presence

8 of hazardous surface scums is a clear advantage of utilising remotely sensed imagery in this

9 context. This study demonstrated that cyanobacterial populations can be detected using

10 remote sensing at concentrations well below those of human health significance. This

11 suggests that remote sensing platforms can contribute to the early-warning monitoring of

12 cyanobacterial populations for human health protection.

\section{Acknowledgements}

15 This research was funded by a grant from the UK Natural Environmental Research Council

16 (NERC) under the Environment and Human Health programme (NE/E009328/1). AISA

17 Eagle and Hawk and CASI-2 data were acquired by NERC's Airborne Research and Survey

18 Facility and preliminary processing was conducted by the Data Analysis Node of NERC's

19 Earth Observation Data Acquisition and Analysis Service at the Plymouth Marine

20 Laboratory. The Freshwater Biological Association generously provided boat access at

21 Esthwaite Water. Kinross Estates kindly provided access to Loch Leven. We thank Bryan

22 Spears, Jack Kelly and Ben James for assisting with fieldwork and Marianne Reilly for

23 microcystin analyses.

\section{References}


1 Alder-Golden, S. M., Matthew, M. W., Bernstein, L. S., Levine, R. Y., Berk, A., Richtsmeier, S. C., Acharya, P. K., Anderson, G. P., Felde, G., Gardner, J., Hoke, M., Jeong, L. S., Pukall, B., Ratkowski, A., \& Burke, H.-H. (1999). Atmospheric correction for shortwave spectral imagery based on MODTRAN4. SPIE Proceedings on Imaging Spectrometry, 3753, 61-69.

Alikas, K. \& Reinart, A. (2008). Validation of the MERIS products on large European lakes: Peipsi, Vanern and Vattern. Hydrobiologia, 599, 161-168.

Bennett, A. \& Bogorad, L. (1973). Complementary chromatic adaptation in a filamentous blue-green-alga. Journal of Cell Biology, 58, 419-435.

Bricaud, A., Babin, M., Morel, A., \& Claustre, H. (1995). Variability in the chlorophyllspecific absorption-coefficients of natural phytoplankton - analysis and parameterization. Journal of Geophysical Research-Oceans, 100, 13321-13332.

Bricaud, A., Claustre, H., Ras, J., \& Oubelkheir, K. (2004). Natural variability of phytoplanktonic absorption in oceanic waters: Influence of the size structure of algal populations. Journal of Geophysical Research-Oceans, 109.

Brient, L., Lengronne, M., Bertrand, E., Rolland, D., Sipel, A., Steinmann, D., Baudin, I., Legeas, M., Le Rouzic, B., \& Bormans, M. (2008). A phycocyanin probe as a tool for monitoring cyanobacteria in freshwater bodies. Journal of Environmental Monitoring, $10,248-255$.

Brierley, B., Carvalho, L., Davies, S., \& Krokowski, J. (2007). Guidance on the quantitative analysis of phytoplankton in freshwater samples. In Phytoplankton Classification Tool (Phase 2). Final Report to SNIFFER (pp. 63-88). Edinburgh: SNIFFER. 
1 Buiteveld, H., Hakvoort, J. H. M., \& Donze, M. (1994). The optical properties of pure water. Ocean Optics XII, 2258, 174-183.

3 Carmichael, W. W., Azevedo, S. M. F. O., An, J. S., Molica, R. J. R., Jochimsen, E. M., Lau, S., Rinehart, K. L., Shaw, G. R., \& Eaglesham, G. K. (2001). Human fatalities from cyanobacteria: Chemical and biological evidence for cyanotoxins. Environmental Health Perspectives, 109, 663-668.

Carvalho, L. \& Kirika, A. (2003). Changes in shallow lake functioning: response to climate change and nutrient reduction. Hydrobiologia, 506, 789-796.

Codd, G. A., Azevedo, S. M. F. O., Bagchi, S. N., Burch, M. D., Carmichael, W. W., Harding, W. R. et al. (2005a). CyanoNet: A global network for cyanobacterial bloom and toxin risk management. International Hydrologolical Programme. Initial situation assessment and recommendations. (Rep. No. 76). UNESCO, Paris.

Codd, G. A., Metcalf, J. S., \& Beattie, K. A. (1999). Retention of Microcystis aeruginosa and microcystin by salad lettuce (Lactuca sativa) after spray irrigation with water containing cyanobacteria. Toxicon, $37,1181-1185$.

Codd, G. A., Morrison, L. F., \& Metcalf, J. S. (2005b). Cyanobacterial toxins: risk management for health protection. Toxicology and Applied Pharmacology, 203, 264272.

Dall'Olmo, G. \& Gitelson, A. A. (2005). Effect of bio-optical parameter variability on the remote estimation of chlorophyll-a concentration in turbid productive waters: experimental results. Applied Optics, 44, 412-422. 
1 Dall'Olmo, G. \& Gitelson, A. A. (2006). Effect of bio-optical parameter variability and uncertainties in reflectance measurements on the remote estimation of chlorophyll-a concentration in turbid productive waters: modeling results. Applied Optics, 45, 35773592.

Dall'Olmo, G., Gitelson, A. A., \& Rundquist, D. C. (2003). Towards a unified approach for remote estimation of chlorophyll-a in both terrestrial vegetation and turbid productive waters. Geophysical Research Letters, 30.

Dekker, A. G. (1993). Hyperspectral Remote Sensing of Inland Water Quality. The Netherlands: Vrije University, Amsterdam.

Ferguson, C. A., Carvalho, L., Scott, E. M., Bowman, A. W., \& Kirika, A. (2008). Assessing ecological responses to environmental change using statistical models. Journal of Applied Ecology, 45, 193-203.

Fogg, G. E., Stewart, W. D. P., Fay, P., \& Walsby, A. E. (1973). The Blue-Green Algae. London and New York: Academic Press.

Gitelson, A. A., Dall'Olmo, G., Moses, W., Rundquist, D. C., Barrow, T., Fisher, T. R., Gurlin, D., \& Holz, J. (2008). A simple semi-analytical model for remote estimation of chlorophyll-a in turbid waters: Validation. Remote Sensing of Environment, 112, $3582-3593$.

Gitelson, A. A., Vina, A., Verma, S. B., Rundquist, D. C., Arkebauer, T. J., Keydan, G., Leavitt, B., Ciganda, V., Burba, G. G., \& Suyker, A. E. (2006). Relationship between gross primary production and chlorophyll content in crops: Implications for the synoptic monitoring of vegetation productivity. Journal of Geophysical ResearchAtmospheres, 111. 
1 Gons, H. J. (1999). Optical teledetection of chlorophyll a in turbid inland waters. Environmental Science \& Technology, 33, 1127-1132.

3 Gons, H. J., Auer, M. T., \& Effler, S. W. (2008). MERIS satellite chlorophyll mapping of oligotrophic and eutrophic waters in the Laurentian Great Lakes. Remote Sensing of Environment, 112, 4098-4106.

6 Gordon, H. R., Brown, O. B., \& Jacobs, M. M. (1975). Computed relationships between 7 8 inherent and apparent optical properties of a flat homogeneous ocean. Applied Optics, $14,417-427$.

9 Havens, K. E. (2008). Cyanobacterial blooms: effects on aquatic ecosystems. In H.K.Hudnell (Ed.), Cyanobacterial Harmful Algal Blooms: State of the Science and Research Needs (pp. 733-747). Berlin: Springer-Verlag.

Hillebrand, H., Durselen, C. D., Kirschtel, D., Pollingher, U., \& Zohary, T. (1999). Biovolume calculation for pelagic and benthic microalgae. Journal of Phycology, 35,

Hunter, P. D., Tyler, A. N., Gilvear, D. J., \& Willby, N. J. (2009). Using remote sensing to aid the assessment of human health risks from blooms of potentially-toxic cyanobacteria. Environmental Science \& Technology, 43, 2627-2633. discrimination of phytoplankton colour groups: The effect of suspended particulate matter and sensor spectral resolution. Remote Sensing of Environment, 112, 15271544. 
1 Hunter, P. D., Tyler, A. N., Willby, N. J., \& Gilvear, D. J. (2008b). The spatial dynamics of vertical migration by Microcystis aeruginosa in a eutrophic shallow lake: A case study using high spatial resolution time-series airborne remote sensing. Limnology and Oceanography, 53, 2391-2406.

Izydorczyk, K., Tarczynska, M., Jurczak, T., Mrowczynski, J., \& Zalewski, M. (2005). Measurement of phycocyanin fluorescence as an online early warning system for cyanobacteria in reservoir intake water. Environmental Toxicology, 20, 425-430.

Jiang, H. B. \& Qiu, B. S. (2005). Photosynthetic adaptation of a bloom-forming cyanobacterium Microcystis aeruginosa (Cyanophyceae) to prolonged UV-B exposure. Journal of Phycology, 41, 983-992.

John, D. M., Whitton, B. A., \& Brook, A. J. (2003). The freshwater algal flora of the British Isles: an identification guide to freshwater and terrestrial algae. Cambridge: Cambridge University Press.

Johnk, K. D., Huisman, J., Sharples, J., Sommeijer, B., Visser, P. M., \& Stroom, J. M. (2008). Summer heatwaves promote blooms of harmful cyanobacteria. Global Change Biology, 14, 495-512.

Kaufman, Y. J., Wald, A. E., Remer, L. A., Gao, B. C., Li, R. R., \& Flynn, L. (1997). The MODIS 2.1-mu m channel - Correlation with visible reflectance for use in remote sensing of aerosol. IEEE Transactions on Geoscience and Remote Sensing, 35, 12861298.

Kutser, T. (2004). Quantitative detection of chlorophyll in cyanobacterial blooms by satellite remote sensing. Limnology and Oceanography, 49, 2179-2189. 
1 Kutser, T. (2009). Passive optical remote sensing of cyanobacteria and other intense phytoplankton blooms in coastal and inland waters. International Journal of Remote Sensing, 30, 4401-4425.

Kutser, T., Metsamaa, L., Strombeck, N., \& Vahtmae, E. (2006). Monitoring cyanobacterial blooms by satellite remote sensing. Estuarine Coastal and Shelf Science, 67, 303-312.

Lorenzen, C. J. (1967). Determination of chlorophyll and pheo-pigments spectrophotometric equations. Limnology and Oceanography, 12, 343-346.

Metcalf, J. S., Banack, S. A., Lindsay, J., Morrison, L. F., Cox, P. A., \& Codd, G. A. (2008). Co-occurrence of beta-N-methylamino-L-alanine, a neurotoxic amino acid with other cyanobacterial toxins in British waterbodies, 1990-2004. Environmental Microbiology, 10, 702-708.

Metcalf, J. S., Bell, S. G., \& Codd, G. A. (2000). Production of novel polyclonal antibodies against the cyanobacterial toxin microcystin-LR and their application for the detection and quantification of microcystins and nodularin. Water Research, 34, 2761-2769.

Metcalf, J. S. \& Codd, G. A. (2000). Microwave oven and boiling waterbath extraction of hepatotoxins from cyanobacterial cells. FEMS Microbiology Letters, 184, 241-246.

Nair, A., Sathyendranath, S., Platt, T., Morales, J., Stuart, V., Forget, M. H., Devred, E., \& Bouman, H. (2008). Remote sensing of phytoplankton functional types. Remote Sensing of Environment, 112, 3366-3375.

Paerl, H. W. \& Huisman, J. (2008). Climate - Blooms like it hot. Science, 320, 57-58. 
1 Patel, A., Mishra, S., Pawar, R., \& Ghosh, P. K. (2005). Purification and characterization of C-phycocyanin from cyanobacterial species of marine and freshwater habitat. Protein Expression and Purification, 40, 248-255.

4

Pearson, M. J., Bateman, I. J., \& Codd, G. A. (2001). Measuring the recreational and amenity values affected by toxic cyanobacteria: a contingent valuation study of Rutland Water, Leicestershire. In R.K.Turner, I. J. Bateman, \& W. N. Adger (Eds.), Economics of Coastal and Water Resources: Valuing Environmental Functions (pp. 67-89). Dordrecht, The Netherlands: Kluwer.

Pilotto, L. S., Douglas, R. M., Burch, M. D., Cameron, S., Beers, M., Rouch, G. J., Robinson, P., Kirk, M., Cowie, C. T., Hardiman, S., Moore, C., \& Attewell, R. G. (1997). Health effects of exposure to cyanobacteria (blue-green algae) during recreational waterrelated activities. Australian and New Zealand Journal of Public Health, 21, 562-566.

Ramos, A. G., Martel, A., Codd, G. A., Soler, E., Coca, J., Redondo, A., Morrison, L. F., Metcalf, J. S., Ojeda, A., Suarez, S., \& Petit, M. (2005). Bloom of the marine diazotrophic cyanobacterium Trichodesmium erythraeum in the Northwest African upwelling. Marine Ecology-Progress Series, 301, 303-305.

Randolph, K., Wilson, J., Tedesco, L., Li, L., Pascual, D. L., \& Soyeux, E. (2008). Hyperspectral remote sensing of cyanobacteria in turbid productive water using optically active pigments, chlorophyll a and phycocyanin. Remote Sensing of Environment, 112, 4009-4019.

Rantajarvi, E., Olsonen, R., Hallfors, S., Leppanen, J. M., \& Raateoja, M. (1998). Effect of sampling frequency on detection of natural variability in phytoplankton: unattended 

high-frequency measurements on board ferries in the Baltic Sea. Ices Journal of Marine Science, 55, 697-704.

Rapala, J., Sivonen, K., Lyra, C., \& Niemela, S. I. (1997). Variation of microcystins, cyanobacterial hepatotoxins, in Anabaena spp. as a function of growth stimuli. Applied and Environmental Microbiology, 63, 2206-2212.

Raps, S., Wyman, K., Siegelman, H. W., \& Falkowski, P. G. (1983). Adaptation of the cyanobacterium Microcystis aeruginosa to light-intensity. Plant Physiology, 72, 829832.

Reinart, A. \& Kutser, T. (2006). Comparison of different satellite sensors in detecting cyanobacterial bloom events in the Baltic Sea. Remote Sensing of Environment, 102, 74-85.

Ruiz-Verdu, A., Simis, S. G. H., de Hoyos, C., Gons, H. J., \& Pena-Martinez, R. (2008). An evaluation of algorithms for the remote sensing of cyanobacterial biomass. Remote Sensing of Environment, 112, 3996-4008.

Sarada, R., Pillai, M. G., \& Ravishankar, G. A. (1999). Phycocyanin from Spirulina sp: influence of processing of biomass on phycocyanin yield, analysis of efficacy of extraction methods and stability studies on phycocyanin. Process Biochemistry, 34, 795-801.

Sathyendranath, S., Watts, L., Devred, E., Platt, T., Caverhill, C., \& Maass, H. (2004). Discrimination of diatoms from other phytoplankton using ocean-colour data. Marine Ecology-Progress Series, 272, 59-68. 
1 Schalles, J. F. \& Yacobi, Y. Z. (2000). Remote detection and seasonal patterns of phycocyanin, carotenoid and chlorophyll pigments in eutrophic waters. Archiv fur Hydrobiologie Special Issues Advances in Limnology, 55, 153-168.

Simis, S. G. H., Peters, S. W. M., \& Gons, H. J. (2005). Remote sensing of the cyanobacterial pigment phycocyanin in turbid inland water. Limnology and Oceanography, 50, 237245.

Simis, S. G. H., Ruiz-Verdu, A., Dominguez-Gomez, J. A., Pena-Martinez, R., Peters, S. W. M., \& Gons, H. J. (2007). Influence of phytoplankton pigment composition on remote sensing of cyanobacterial biomass. Remote Sensing of Environment, 106, 414-427.

Smyth, T. J., Moore, G. F., Groom, S. B., Land, P. E., \& Tyrrell, T. (2002). Optical modeling and measurements of a coccolithophore bloom. Applied Optics, 41, 7679-7688.

Tomlinson, M. C., Wynne, T. T., \& Stumpf, R. P. (2009). An evaluation of remote sensing techniques for enhanced detection of the toxic dinoflagellate, Karenia brevis. Remote Sensing of Environment, 113, 598-609.

Tyler, A. N., Hunter, P. D., Carvalho, L., Codd, G. A., Elliott, J. A., Ferguson, C. A., Hanley, N. D., Hopkins, D. W., Maberly, S. C., Mearns, K. J., \& Scott, E. M. (2009). Strategies for monitoring and managing mass populations of toxic cyanobacteria in recreational waters: a multi-interdisciplinary approach. Environmental Health, 8 (Suppl. 1), S11.

Tyler, A. N., Svab, E., Preston, T., Presing, M., \& Kovacs, W. A. (2006). Remote sensing of the water quality of shallow lakes: A mixture modelling approach to quantifying phytoplankton in water characterized by high-suspended sediment. International Journal of Remote Sensing, 27, 1521-1537. 
1 Ward, C. J. (1999). Investigations into the toxicology and persistence of microcystins. $\mathrm{PhD}$ Thesis, University of Dundee, Scotland.

3 Westberry, T. K., Siegel, D. A., \& Subramaniam, A. (2005). An improved bio-optical model for the remote sensing of Trichodesmium spp. blooms. Journal of Geophysical Research-Oceans, 110.

6 WHO (2003). Guidelines for safe recreational water environments. Vol. 1, Coastal and fresh 7 waters Geneva: World Health Organisation.

8 WHO (2004). Guidelines for drinking-water quality (Rep. No. Vol. 1). Geneva: WHO.

9 Wiedner, C., Visser, P. M., Fastner, J., Metcalf, J. S., Codd, G. A., \& Mur, L. R. (2003).

10 Effects of light on the microcystin content of Microcystis strain PCC 7806. Applied and Environmental Microbiology, 69, 1475-1481. 